\title{
Hydrodynamic Simulation of Oil Blowout and Response Action to Evaluate Environmental Consequences on Prawns
}

\author{
Mehdi Shafieefar ${ }^{1 *}$, Pooya Ranjbar ${ }^{2}$ \\ 1*Professor, Tarbiat Modares University; shafiee@modares.ac.ir \\ ${ }^{2}$ Offshore Structural Engineer, Saff-Rosemond; pooya.ranjbar@gmail.com
}

\section{ARTICLE INFO}

Article History:

Received: 23 Oct. 2017

Accepted: 12 Jul. 2018

\section{Keywords:}

Pipeline Oil Spill

Response Action

Hydrodynamic Simulation

Marine Pollution

Prawn

\begin{abstract}
A scenario-specific modeling of oil blowout from the Khark island pipelines in the Persian Gulf has been carried out to evaluate the environmental impact of oil spill on the local coast, seabed and prawns. Also, various scenarios for response actions have been considered. The analyses have been performed by SINTEF Oil Spill Contingency and Response (OSCAR), a 3-dimensional model system. At the first step, OSCAR as the oil spill analysis model was successfully verified in the Persian Gulf using Mina Al-Ahmadi oil spill field observed data. The oil path and predicted time resulted from the OSCAR model were in a very good agreement with the field observed data. Results related to the scenarios of oil blowout from the Khark Island pipelines indicate that the wind is the key factor for advection and spreading of oil in the area. Due to wind conditions in Khark area, the Khark South-East coast has the maximum oil contamination potential. The results show the spilled oil may extremely threat the Khark area environment and especially the local prawns due to the high concentration of hydrocarbons in the water column. The reason for high level of entrainment and dispersion of oil in the water column is the possibility of high-speed blowout from the pipeline in form of a jet. Results indicates that the response action not only may have a low efficiency to reduce the potential environmental damages on the coast, but also may increase the potential environmental hazards on the local prawns due to the utilization of chemical dispersants.
\end{abstract}

\section{Introduction}

Oil is a vital production for the modern society. However, this resource could destroy marine life, economy, and environment if becomes out of control and also could be one of the most destructive pollutant substances for the environment. Many countries have contingency plan aiming to prevent and minimize the environmental pollution due to the oil spill in the sea. Numerical models as a tool for contingency plan are used to predict the trajectory of oil particles. The oil pollution potential in the Persian Gulf is at a high level due to many offshore oil resources and oil transportation activities. Some studies related to simulation of the oil spill in the Persian Gulf are summarized in the following paragraph.

Lehr and Cekirge [1] used GULFSLIK I model for simulating oil spill trajectory in the Persian Gulf, Saudi Arabia. Al-Rabeh et al. [2] used both GULFSLIK II and OILPOL models to simulate the fate of oil spills of Al-Ahmadi in Kuwait. Proctor et al. [3] used a threedimensional model to simulate the fate of oil spills of Al-Ahmadi in Kuwait. Sabbagh Yazdi [4] presented a coupled solution of the oil slick and depth-averaged tidal currents near Siri Island, Persian Gulf. Elhakeem et al. [5] presented the results of simulation of AlAhmadi historical oil spill crisis in the Persian Gulf by MIKE3-SA. Howlett et al. [6] used OILMAP model to forecast oil spill in Dubai region of Persian Gulf. They employed a 3-D rectilinear hydrodynamic model in conjunction with oil spill model. Badri and Azimian [7] presented an oil spill model based on the Kelvin wave theory and artificial wind field for Northern part of the Iranian waters of Persian Gulf. Farzingohar et al. [8] used GNOME model for simulating an oil spill in Hormozgan waters. Ranjbar et al. [9] presented analyses of specific hypothetical blowout scenarios related to subsea oil pipelines between the coast of the mainland of Iran and Khark Island in the Persian Gulf to evaluate of planned response actions and strategies for decreasing environmental consequences of spilled oil on Khark island area. Rezvandoost et al. [10] used OSIS to analyses of the particular hypothetical oil spill in Bahregansar offshore oilfield in the Persian Gulf. Present study is an objective basis for analyses of 
planned response actions and strategies for reducing the environmental impacts of the oil spill on Khark area. A scenario-specific modeling was carried out to evaluate potential effects due to an oil spill from seabed pipelines between Iran mainland coast and Khark Island (Figure 1). The scenarios are selected in a way to represent a practical analysis to evaluate the environmental impact of oil spill on the local coast, seabed and mainly on the local prawns. Moreover, some oil spill scenarios are investigated to evaluate the efficiency of oil spill contingency planning for response actions in decreasing potential consequences. The subsea oil blowout and its movement through the water column to the surface which behaves as a jet (due to momentum and buoyancy) or a plume (due to buoyancy) was modeled by DEEPBLOW model embedded in OSCAR. In all scenarios, the spill analysis simulation covers the case study period from January 02, 1994 to February 01, 1994.

In order to verify the OSCAR model, OSCAR simulation results of Mina Al-Ahmadi oil spill in the Persian Gulf during the Persian Gulf War were compared with both the actual data of oil slick movement and the GULFSLIK II model simulation results. DEEPBLOW model has already been verified by Ranjbar et al. [11].

\section{Materials and Methods}

Khark Island is the biggest Iran's oil export terminal and is located about $57 \mathrm{~km}$ North-West of Boushehr and about $40 \mathrm{~km}$ South of Ganaveh port (Figure 1). Approximately $90 \%$ of crude oil of Iran is transported from the mainland to Khark Island by 5 pipelines and is exported from Khark by Tankers. The mean water depth in this area is $20 \mathrm{~m} \mathrm{[12].} \mathrm{This} \mathrm{area} \mathrm{has} \mathrm{a} \mathrm{high}$ potential of oil blowout from pipelines due to probable events such as earthquake, accidental impact and corrosion.

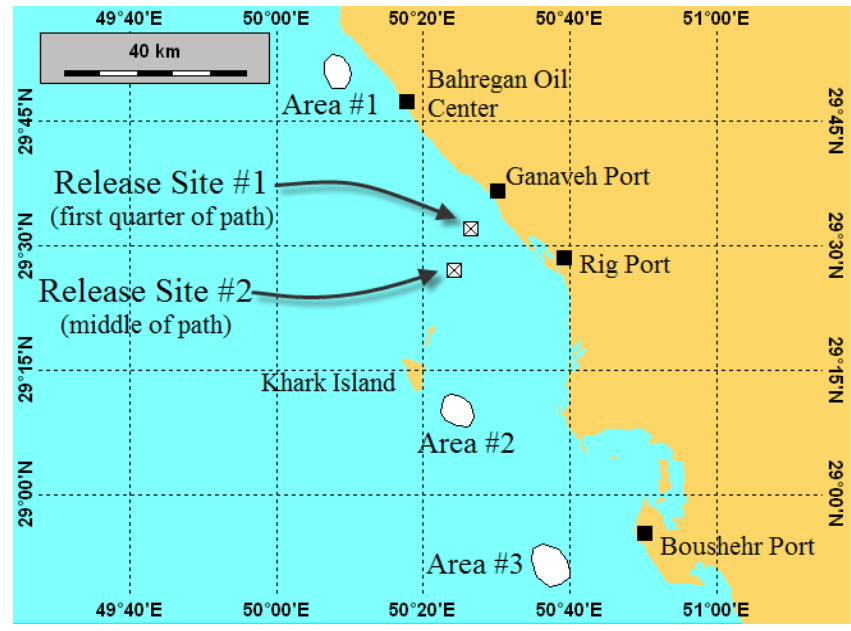

Figure 1. Protected areas and release sites

Modeling of hypothetical oil spills was performed by OSCAR 3-Dimensional model. The OSCAR model system ([13], [14]) has been developed to supply a tool for objective analysis of alternative spill response strategies. OSCAR is a tool that directly and objectively addresses this trade-off. Key components of the OSCAR are weathering model ([15], [16]), a 3Dimensional oil trajectory and chemical fates model [17], DEEPBLOW model [18], and an oil spill combat model ([19], [14]). OSCAR employs surface spreading, advection, entrainment, emulsification, and volatilization algorithms to determine transport and fate on the surface. In the water column, horizontal and vertical advection and dispersion of entrained and dissolved hydrocarbons are simulated by random walk procedures. Partitioning between particulate-absorbed and dissolved state is calculated based on the linear equilibrium theory. The contaminant fraction that is absorbed to suspended particulate matter settles with the particles. Contaminants at the bottom are mixed into the underlying sediments and may be dissolved back into the water. Degradation in water and sediments is represented as a first-order decay process. In this research, simulation of subsurface wind-driven currents has been performed by Ekman model which is embedded in OSCAR model. Simulation of the tidal current has been performed by a hydrodynamic module of the MIKE21 model which is called MIKE21-HD. MIKE21-HD works based on the numerical solution of the two-dimensional incompressible Reynolds averaged Navier-Stokes equations invoking the assumptions of Boussinesq and hydrostatic pressure [20]. The current hydrodynamic model of Persian Gulf was forced with water level boundary based on the recording of measured water level near Cahabar port [21]. The water level variation along the boundary line was considered same as the recording of the measured water level near Cahaba port. The model processed on a triangular mesh from January 02, 1994 to February 01,1994 using a simulation time step of 5 minutes. The maximum depth-averaged velocity of tidal current in Khark area is $0.55 \mathrm{~m} / \mathrm{sec}$. In order to increase the accuracy, an equivalent current profile velocity with a logarithmic distribution in depth (with zero value at the seabed) was used as the current input for OSCAR model. Data of wind-driven and tidal currents were used as variable inputs in terms of value and direction for the simulations.

Prevailing wind direction in Khark area blows from North-West towards South-East with an average speed of $4 \mathrm{~m} / \mathrm{sec}$ in January. For wind input (speed and direction), the atmospheric model data from ECMWF [22] was used. In this study, input data was prepared with a grid size of $2.5^{\circ}$ by $2.5^{\circ}$. The wind data covered the time period from January 02, 1994 to February 01, 1994 with 6 hours' time step. Wind data was used as variable inputs in terms of value and direction for the simulations.

In January, average water column temperature is $16^{\circ} \mathrm{C}$, air temperature is $30{ }^{\circ} \mathrm{C}$, averaged water column salinity is $35 \mathrm{gr} / \mathrm{lit}$ and averaged water column oxygen 


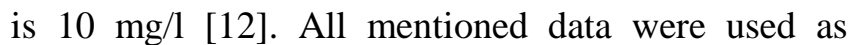
constant for simulations.

The definition of the coastline was limited by the spatial resolution of the underlying map data. The coastal data supplied with the model had a resolution of approximately $1 \mathrm{~km}$. The dataset was derived from the United States Defense Mapping Agency's digital chart of the world (DCW) database [30]. Bathymetry was defined by one or more gridded datasets, stored in a database supplied with the OSCAR model. The dataset supplied with the model, SeaTopo 6.2, covers from 72 degrees $\mathrm{S}$ to 72 degrees $\mathrm{N}$ latitude, provides a resolution of 3 to $10 \mathrm{~km}$ and is based on a combination of satellite altimetry and ship soundings [23]. A sensitivity analysis showed that the difference between the spatial resolution of bathymetry and the coastal line has a negligible effect on the results.

The study area is among of protected environmental zones, Spawning areas and nursery grounds of green tiger prawn (Penaeus Semisulcatus) are considered as the most important protected zones. Green tiger prawn plays an important role in the ecosystem and economy of the region. In addition, this prawn species directly affects human food webs. Nearby the underwater pipelines, there are three important protecting prawn areas including Genaveh area (area \#1), Hele area (area \#2), and Boushehr area (area \#3), (see Figure 1). The prawns live in a depth between 20 to 30 meters and are highly exposed to the oil pollution. Mentioned areas are considered to meet the criteria of the contingency plan and to evaluate the efficiency of the oil spill response operation.

OSCAR allows the assignment of specific operational strategies to each boom-skimmer or dispersant vessels system in the process of simulation. Characteristics of boom-skimmer systems, dispersant vessels and dispersant aircraft (owned by HSE department of Khark area) that participated in the response action are outlined in Table 1. It is assumed that recovery efficiency is dependent on the significant wave height ([24], [25]). In OSCAR, it is computed as a function of wind speed, wind fetch, and wind duration. Under ideal condition, a maximum of $80 \%$ of the oil entering the boom could be recovered. Effectiveness is reduced as the wave height (or wind speed) increases and goes to zero at 2-meter wave height, or a wind speed a little over $10 \mathrm{~m} / \mathrm{sec}$ ( 20 knots). It is further assumed that operation ceases at night (i.e. that infrared monitoring equipment is not available). OSCAR computes sunrise and sunset from latitude and longitude and calendar day ([14], [19]).

There are three mechanical recovery equipment systems in the response contingency planning. Two systems are able to be mobilized in 2 hours and the other system are able to be mobilized within 48 hours after announcing the accident. Two recovery systems have a boom with 100 meters length and a skimmer with $30 \mathrm{~m}^{3} / \mathrm{hr}$ pumping capacity, and the other recovery system have a boom with 250-meter length and a skimmer with $40 \mathrm{~m}^{3} / \mathrm{hr}$ pumping capacity. In addition, there are three vessels which contain chemical dispersant with an application rate of $0.5 \mathrm{~m}^{3} / \mathrm{min}$ and there is an aircraft which contains chemical dispersant with an application rate of $0.9 \mathrm{~m}^{3} / \mathrm{min}$. Mobilization time of vessels is 2 hours and mobilization time of aircraft is 48 hours after announcing the accident.

Table 1. Descriptive parameters of boom-skimmers and dispersant vessels and crafts which owned by HSE department of Khark area [12]

\begin{tabular}{|c|c|c|c|}
\hline \multicolumn{4}{|c|}{ Recovery System (RS) } \\
\hline System & $\begin{array}{l}\text { First boom- } \\
\text { skimmer } \\
\text { (1 Nos.) }\end{array}$ & $\begin{array}{c}\text { Second } \\
\text { boom- } \\
\text { skimmer } \\
\text { Nos.) }\end{array}$ & $\begin{array}{c}\text { Third } \\
\text { boom- } \\
\text { skimmer } \\
\text { (1 Nos.) }\end{array}$ \\
\hline $\begin{array}{l}\text { Mobilization } \\
\text { time }\end{array}$ & $2[\mathrm{hr}]$ & $48[\mathrm{hr}]$ & $2[\mathrm{hr}]$ \\
\hline Cruising speed & 12 [knots] & 12 [knots] & $12[\mathrm{knots}]$ \\
\hline $\begin{array}{l}\text { Operational } \\
\text { speed }\end{array}$ & 2 [knots] & 2 [knots] & 2 [knots] \\
\hline Boom opening & $100[\mathrm{~m}]$ & $100[\mathrm{~m}]$ & $250[\mathrm{~m}]$ \\
\hline $\begin{array}{l}\text { Nominal } \\
\text { skimmer } \\
\text { capacity }\end{array}$ & $30\left[\mathrm{~m}^{3} / \mathrm{hr}\right]$ & $30\left[\mathrm{~m}^{3} / \mathrm{hr}\right]$ & $40\left[\mathrm{~m}^{3} / \mathrm{hr}\right]$ \\
\hline Storage capacity & $30\left[\mathrm{~m}^{3}\right]$ & $30\left[\mathrm{~m}^{3}\right]$ & $40\left[\mathrm{~m}^{3}\right]$ \\
\hline $\begin{array}{l}\text { Maximum } \\
\text { operational } \\
\text { wave height }\end{array}$ & $2[\mathrm{~m}]$ & $2[\mathrm{~m}]$ & $2[\mathrm{~m}]$ \\
\hline \multicolumn{4}{|c|}{ Dispersant Vessels (DV) and Dispersant Aircrafts (DA) } \\
\hline System & $\begin{array}{l}\text { Aircraft } \\
\text { (1 Nos.) }\end{array}$ & $\begin{array}{l}\text { Vessel type } \\
1 \text { (2 Nos.) }\end{array}$ & $\begin{array}{l}\text { Vessel type } \\
2 \text { (1 Nos.) }\end{array}$ \\
\hline Application rate & $\begin{array}{c}0.9 \\
{\left[\mathrm{~m}^{3} / \mathrm{min}\right]}\end{array}$ & $0.5\left[\mathrm{~m}^{3} / \mathrm{min}\right]$ & $\begin{array}{c}0.5 \\
{\left[\mathrm{~m}^{3} / \mathrm{min}\right]}\end{array}$ \\
\hline $\begin{array}{l}\text { Mobilization } \\
\text { time }\end{array}$ & $48[\mathrm{hr}]$ & $2[\mathrm{hr}]$ & $2[\mathrm{hr}]$ \\
\hline $\begin{array}{l}\text { Dispersant } \\
\text { tankage }\end{array}$ & $5\left[\mathrm{~m}^{3}\right]$ & $2.7\left[\mathrm{~m}^{3}\right]$ & $2\left[\mathrm{~m}^{3}\right]$ \\
\hline $\begin{array}{l}\text { Operational } \\
\text { wind threshold }\end{array}$ & $30[\mathrm{knot}]$ & - & - \\
\hline Cruise speed & 280 [knot] & 10 [knot] & $12[\mathrm{knot}]$ \\
\hline $\begin{array}{l}\text { Operational } \\
\text { speed }\end{array}$ & 140 [knot] & 2 [knot] & $2[\mathrm{knot}]$ \\
\hline Endurance & 4 [hr.] & - & - \\
\hline Spray width & $25[\mathrm{~m}]$ & $10[\mathrm{~m}]$ & $10[\mathrm{~m}]$ \\
\hline $\begin{array}{l}\text { No. of trips per } \\
\text { day }\end{array}$ & 5 & 10 & 10 \\
\hline $\begin{array}{l}\text { Total available } \\
\text { dispersant }\end{array}$ & $100\left[\mathrm{~m}^{3}\right]$ & $100\left[\mathrm{~m}^{3}\right]$ & $100\left[\mathrm{~m}^{3}\right]$ \\
\hline Effectiveness & $70 \%$ & $70 \%$ & $70 \%$ \\
\hline $\begin{array}{l}\text { Turnaround } \\
\text { time to refilling }\end{array}$ & $1[\mathrm{hr}]$ & $0.5[\mathrm{hr}]$ & $0.5[\mathrm{hr}]$ \\
\hline Dispersant type & $\begin{array}{c}\text { Super } \\
\text { Dispersant } \\
\text { 25 Type } 2 \\
\end{array}$ & $\begin{array}{c}\text { Super } \\
\text { Dispersant } \\
25 \text { Type } 2 \\
\end{array}$ & $\begin{array}{c}\text { Super } \\
\text { Dispersant } \\
\text { 25 Type } 2 \\
\end{array}$ \\
\hline
\end{tabular}

Limitation in using chemical dispersant should be considered in response action and it should be used with caution. Chemical dispersant prevents oil slicks being hit the coastline. It should be used when cleaning of oil slicks from the surface is in a high priority relative to removing of oil droplets in the water column. The response priority is the protection of the prawn areas and the coastline. The oil response scenarios simulated here employed a mixed strategy (see Figure 
6), wherein two boom-skimmer systems and one dispersant aircraft are worked far from the oil spill source and near the coasts downwind. The third boomskimmer system and one dispersant vessel is located near the Hele area which is subjected to the spilled oil more than the other areas. Two other dispersant vessels are located in the vicinity of Khark Island oil terminal. To avoid the return of boom-skimmer systems for offloading the recovered oil, some offload barges are employed in the response action. In order to reduce evaporation of the most volatile and acutely toxic components, the chemical dispersant should be only applied to the oil slicks outside some exclusion zone near the oil blowout source [25].

One pipeline with 30 inches OD (outside diameter) and one pipeline with 52 inches OD transport the Iranian heavy crude oil and three Pipelines (two pipeline with 30 inches OD and one pipeline with 42 inches OD) transport the Iranian light oil crude from Genaveh port to Khark Island with an approximate length of $46 \mathrm{~km}$. The density of light and heavy oil is $0.852 \mathrm{ton} / \mathrm{m}^{3}$ (in temperature of $21^{\circ} \mathrm{C}$ ) and $0.875 \mathrm{ton} / \mathrm{m}^{3}$ (in temperature of $21^{\circ} \mathrm{C}$ ) respectively [12]. Hypothetical blowout from three pipelines including 30 inches OD light oil, 30 inches OD heavy oil and 52 inches OD heavy oil was separately investigated.

The pressure of pipeline at the Genaveh port station is equal to $280 \mathrm{psi}\left(19.7 \mathrm{~kg} / \mathrm{cm}^{2}\right)$ and it is equal to $30 \mathrm{psi}$ $\left(2.1 \mathrm{~kg} / \mathrm{cm}^{2}\right)$ at the Khark Island station [12]. The pipelines have an approximately $204 \mathrm{~m}$ head loss through the length between two stations. Hypothetical blowout from a $5 \mathrm{~cm}$ hole on two pipelines with 30 inches OD (light and heavy oil) was considered at the first quarter of each pipeline (near Genaveh port). In this condition, oil spills with an initial speed of 59 $\mathrm{m} / \mathrm{sec}$ (according to mass conservation and Bernoulli equation) and 63,000 barrels per day would release in the water. To compare the condition of a spill of light crude oil and heavy crude oil, simulation of both oil types were performed separately as scenarios No. 1 and 2 (see Table 2 for detail). The results showed the evaporated oil in scenario No. 1 (light oil spill) was 5\% (9450 barrels) more than the evaporated oil in scenario No. 2 (heavy oil spill). So it is obvious in the case of heavy oil blowout more oil remains in the water environment and its impact would be worse than light oil blowout. Therefore only heavy oil blowout was considered for the other scenarios.

Hypothetical blowout from 52 inches OD heavy oil pipeline was considered to occur in two locations. First blowout location was in the first quarter (near Genaveh port) of pipeline and the second one was in the middle of pipeline between two stations. By an overall rupture of a cross-section of the 52 inches OD heavy oil pipeline at any point in a rout, 137,500 barrels per hour would release in the water [12].

Oil release could be controlled after the announcement of the blowout. A spot of oil blowout from an offshore pipeline requires a permanent mass balance between two stations, or its oil slicks need to be observed. It is not possible to determine the exact blowout duration in Khark area. Available blowout announcement facilities are able to spot the pollution within 3 days after initiation of the blowout depending on the spill rate. To determine blowout duration from pipelines with 30 inches OD, two blowout durations of 3 days and 1 day for heavy oil were considered in scenarios No. 2 and 3 respectively. Their mass balance time-series and distribution of ashore and deposited oil on the seabed for 30 days after the beginning of the hypothetical blowout were almost similar. Because of a higher amount of released oil in scenario No. 2, blowout duration of 3 days was considered for the pipeline with 30 inches OD. For the 52 inches OD pipeline with overall rupture of the cross-section, which has a high probability of spotting due to mass balance between two stations, blowout duration of 8 hours was considered.

Hypothetical oil blowout is assumed to occur in the winter season which is spawning season for the green tiger prawn [26]. Also, the winter has the worst condition of wind history and has the least content of oil evaporation. Therefore the date of January 02, 1994 was selected as the initial day of the blowout in all analyses.

Finally, based on aforementioned considerations, nine scenarios were considered which are outlined in Table 2. The oil spill simulation of all scenarios covers the case study period from January 02, 1994 to February 01, 1994 using a time step of 300 seconds.

The model processed on a rectangular grid that each cell dimension was $1.0 \mathrm{~km}$ in North-South direction and $1.0 \mathrm{~km}$ in East-West direction.

In order to verify the OSCAR model, an oil spill of AlAhmadi in the Persian Gulf during Persian Gulf War over the period of January-May 1991 was simulated by OSCAR model in conjunction with MIKE21 current hydrodynamic data and wind data from Elhakeem et al. [5]. The results then were compared with the actual data of oil slick movement and GULFSLIK II model simulation results [5]. The volume of spilled oil from Al-Ahmadi oil field was estimated as large as $6 \times 106$ barrels by [5]. The spill analysis covers the case study period from January 19, 1991, to March 18, 1991, using a simulation time step of 5 minutes.

\section{Governing Equations}

OSCAR uses Lagrangian particles to solve the transport equation (Eq. 1):

$$
\frac{\delta C_{i}}{\delta t}+\vec{V} \cdot \vec{\nabla} C_{i}=\vec{\nabla} \cdot D_{k} \vec{\nabla} C_{i}+\sum_{j=1}^{n} r_{j} C_{i}+\sum_{j=1}^{n} \sum_{i=1}^{n} r_{i j} C_{i}
$$

Where in Eq.(1) $C_{i}$ is the concentration of $i^{\text {th }}$ chemical component, $\mathrm{D}_{\mathrm{k}}$ is the turbulent dispersion coefficient in three direction $\mathrm{x}, \mathrm{y}$, and $\mathrm{z}$, is advection velocity vector and $r_{j}$ is $j_{\text {th }}$ process rate including evaporation, dissolution, degradation, and sedimentation. The 
Table 2. Selected scenarios

\begin{tabular}{cccccccc}
\hline No. & $\begin{array}{c}\text { Oil } \\
\text { type }\end{array}$ & Released oil & $\begin{array}{c}\text { Specification of } \\
\text { response }\end{array}$ & $\begin{array}{c}\text { Blowout } \\
\text { duration }\end{array}$ & $\begin{array}{c}\text { Release } \\
\text { location }\end{array}$ & $\begin{array}{c}\text { Time for first } \\
\text { oil to hit coast }\end{array}$ & $\begin{array}{c}\text { Maximum oil } \\
\text { ashore (of total) }\end{array}$ \\
\hline 1 & Light & $189,000[$ Barrels] & No response & $72[\mathrm{hr}]$ & First quarter & $5[$ day] & $7.7 \%$ \\
\hline 2 & Heavy & $189,000[$ Barrels] & No response & $72[\mathrm{hr}]$ & First quarter & $5[$ day] & $8.0 \%$ \\
\hline 3 & Heavy & $63,000[$ Barrels] & No response & $24[\mathrm{hr}]$ & First quarter & $5[$ day] & $5.9 \%$ \\
\hline 4 & Heavy & $189,000[$ Barrels] & 3 RS & $72[\mathrm{hr}]$ & First quarter & $5[$ day] & $3.5 \%$ \\
\hline 5 & Heavy & $189,000[$ Barrels] & $\begin{array}{c}3 \text { RS, 3 DV, and } \\
\text { one DA }\end{array}$ & $72[\mathrm{hr}]$ & First quarter & $5[$ day] & $3.2 \%$ \\
\hline $6^{*}$ & Heavy & $189,000[$ Barrels] & $\begin{array}{c}3 \text { RS, 3 DV, and } \\
\text { one DA }\end{array}$ & $72[\mathrm{hr}]$ & First quarter & $5[$ day] & $5.0 \%$ \\
\hline 7 & Heavy & $1,100,000[$ Barrels] & No response & $8[\mathrm{hr}]$ & First quarter & $4.7[$ day] & $31.3 \%$ \\
\hline 8 & Heavy & $1,100,000[$ Barrels] & No response & $8[\mathrm{hr}]$ & Middle & - & 0.0 \\
\hline 9 & Heavy & $1,100,000[$ Barrels] & $\begin{array}{c}3 \text { RS, } 3 \text { DV, and } \\
\text { one DA }\end{array}$ & $8[\mathrm{hr}]$ & Middle & - & 0.0 \\
\hline
\end{tabular}

* All response equipment is able to be mobilized within 48 hours after announcing the accident.

algorithms used to simulate these processes and controlling physical fates of substances have been described by Aamo et al. [15] and Reed et al. ([13], [17], [27], [28]).

\section{Results and Discussion}

A comparison between actual and predicted trajectories of the oil spill of Al-Ahmadi over the period from January 19, 1991, to March 18, 1991, is shown in Figure 2. The oil path and predicted time results of the OSCAR model are in a very good agreement with the data of field observation in the three first stations of Khafji, Safania, and Ras Al Ghar until the first week of February. Difference between the fields observed data and OSCAR model predictions were initiated after that date. Generally, the oil slick track predicted by OSCAR is closer to the field observed data compared with GULFSLIKII. The oil slick reached the Abu Ali Island in both OSCAR and the field observation trajectories.
The results of the OSCAR are reliable when it performs in conjunction with MIKE21 current hydrodynamic data and reliable wind data. As a result, OSCAR is an appropriate tool to predict oil spill trajectory in the Persian Gulf with a high accuracy. Accordingly, the nine defined scenarios (Table 2) were simulated. Results of these simulations are discussed hereafter. According to mass balance time-series related to scenarios No. 2 to 6 (Figure 3), a major part of the spilled oil (15\%) is evaporated within the first 6 days of the simulation. A significant part of the oil is polluted to the environment by dispersion in the water column, depositing on the seabed and reaching the Khark area beach. The main factor in the high volume of oil deposition on the seabed is the high-speed jet of blowout oil from the pipeline [19]. This leads to an intense entrainment and dispersion of the oil in the water column. As a result, in Khark area with shallow water depth (less than $30 \mathrm{~m}$ ), high dispersion in the

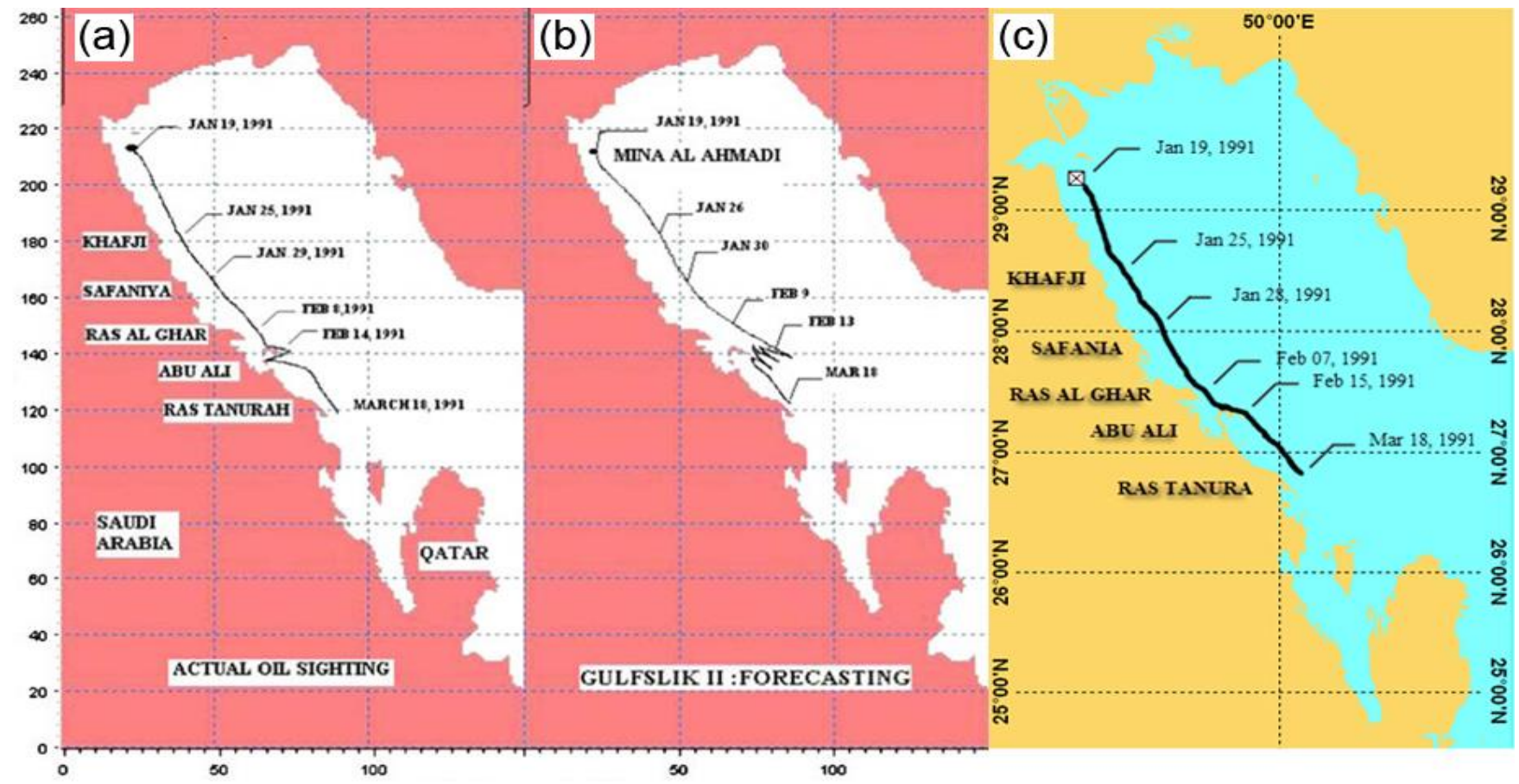

Figure 2. Comparison between real oil spill trajectory (a) [29], oil spill trajectory simulated by GULFSLIK model (b) [29], oil spill trajectory simulated by OSCAR model (c) [Ranjbar et al.] during January 19, 1991, to March 18, 1991 
(a)

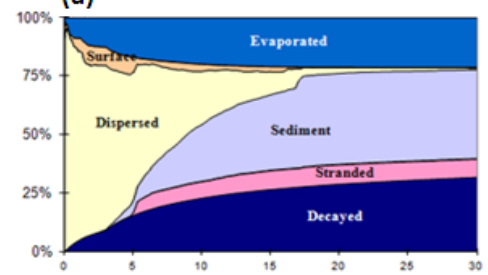

(b)

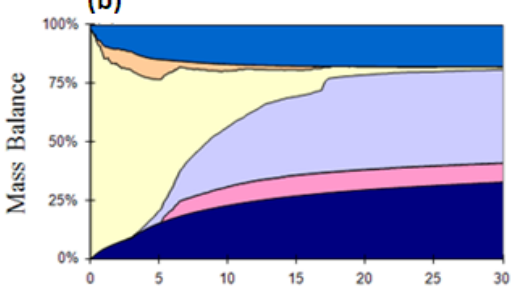

(c)

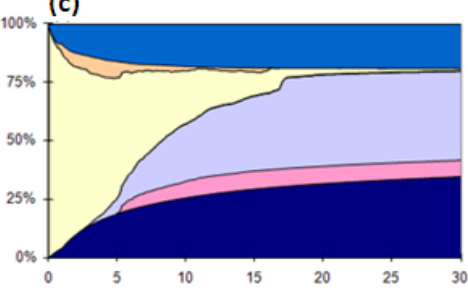

(d)

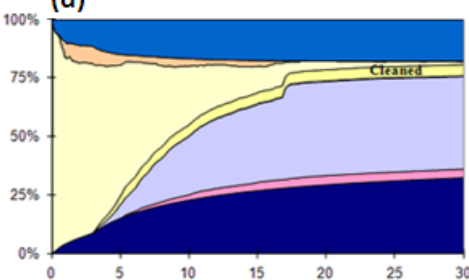

(e)

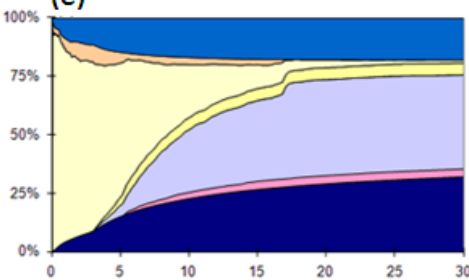

(f)

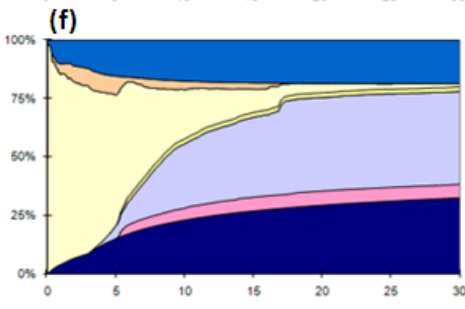

(g)

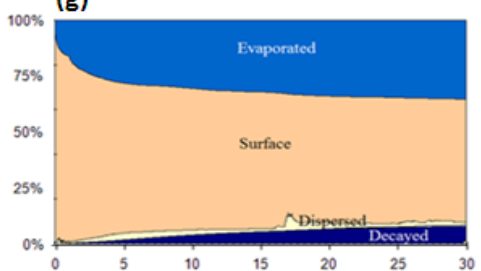

(h)

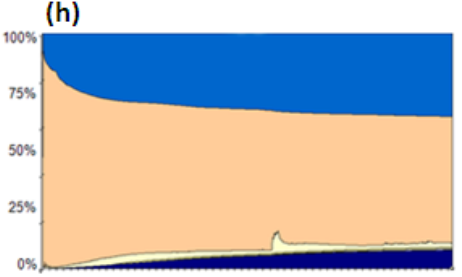

(i)

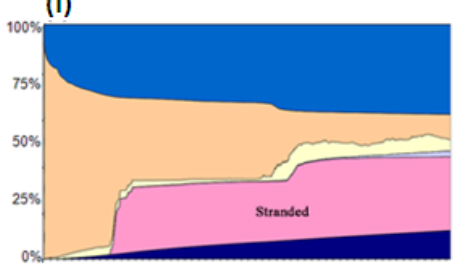

Time (days)

Figure 3. Mass balance time-series of blowout simulation: (a) scenario No. 1; (b) scenario No. 2; (c) scenario No. 3; (d) scenario No. 4; (e) scenario No. 5; (f) scenario No. 6; (g) scenario No. 8; (h) scenario No. 9; (i) scenario No. 7

water column leads the deposition of a major part of oil on the seabed in the form of sediment.

Figure 4 shows a snapshot of the surface and subsurface distribution oil in scenario No. 2. For the first time, oil reached the coast 5 days after the hypothetical blowout. Currents are the major component in the vertical distribution and the horizontal mixing of the oil in the water column, but wind has a minor impact on it. 5 days after the blowout in this scenario, the maximum oil concentration was $50 \mathrm{ppm}$ and the oil concentration contours were distributed in the entire water column. In scenario No. 2, $8 \%$ (15,120 barrels, or 2,100 tones) of the spilled oil stranded the coast just 30 days after the hypothetical blowout which resulted to the maximum linear loading of $10 \mathrm{~kg} / \mathrm{m}$ on the shoreline (Figure 5). A major part of the spilled oil (40\%) was deposited on the seabed as sediment with maximum sediment accumulation of $120 \mathrm{gr} / \mathrm{m} 2$.

Scenario No. 2 was modeled without considering the potential effects of wind (Figure 4). Oil is moved in the surface and water column reciprocates with the currents in this simulation and as a result, the spilled oil remained nearby the source. After 30 days, less than $1 \%$ of the spilled oil reached the North-West coast. Results of scenario 2 with and without considering wind indicate that the wind is a major factor in the transport and spread of oil in the Khark area.

Figure 4 shows a snapshot of the surface and subsurface distribution of heavy oil in scenario No. 8 (see Table 2 ). Due to low entrainment and high volume of spilled oil, dispersion of oil in the water column is at a low level. A major part of spilled oil remains on the water surface during the simulation and a major part of spilled oil is evaporated. Just a minor part of the spilled oil
$(0.3 \%)$ is deposited on the seabed with a maximum sediment accumulation of $2.5 \mathrm{gr} / \mathrm{m} 2$ (Figure 5) after 30 days. Oil on the water surface is moved towards the South-East with no impact on Khark South-East coast and is reached to an area $240 \mathrm{~km}$ far from the source in 30 days. In this scenario, the potential of oil effects on the Khark area is very low.

In scenario No. 7, the impact of oil spill on the coast is high in contrast to scenario No. 8. 30 days after the hypothetical blowout in this scenario, a major part of spilled oil (31.3\%) is stranded the coasts, a minor part of it $(2.5 \%)$ is deposited on the seabed and $38.2 \%$ is evaporated. The reason for trapping of the high volume of oil on the coast is the presence of the South-East coastline cape on the path of the oil slicks towards South-East. Thus, by changing the position of the oil blowout, the effect of oil on the Khark area coastline would extremely change.

The sediment threats the Khark seabed habitats, especially prawns (see Figure 5). As it was mentioned before, a major part of the spilled oil will be deposited on the seabed in scenario No. 2. The maximum accumulation of hydrocarbon sediment was $0.06 \mathrm{gr} / \mathrm{m} 2$ and $0.150 \mathrm{gr} / \mathrm{m} 2$ in scenarios No. 2 and 8 respectively. There was no hydrocarbon sedimentation in the area \#3 in scenario No. 2. According to the high amount of oil dispersion in the water column in scenario No. 2, a significant part of the oil droplets is moved upwind by the current. This causes slight oil sedimentation on the seabed at the area \#1 with a maximum sediment accumulation of $0.5 \mathrm{gr} / \mathrm{m} 2$. However, the hydrocarbon sedimentation does not affect the area \#1 in scenario No. 8. 


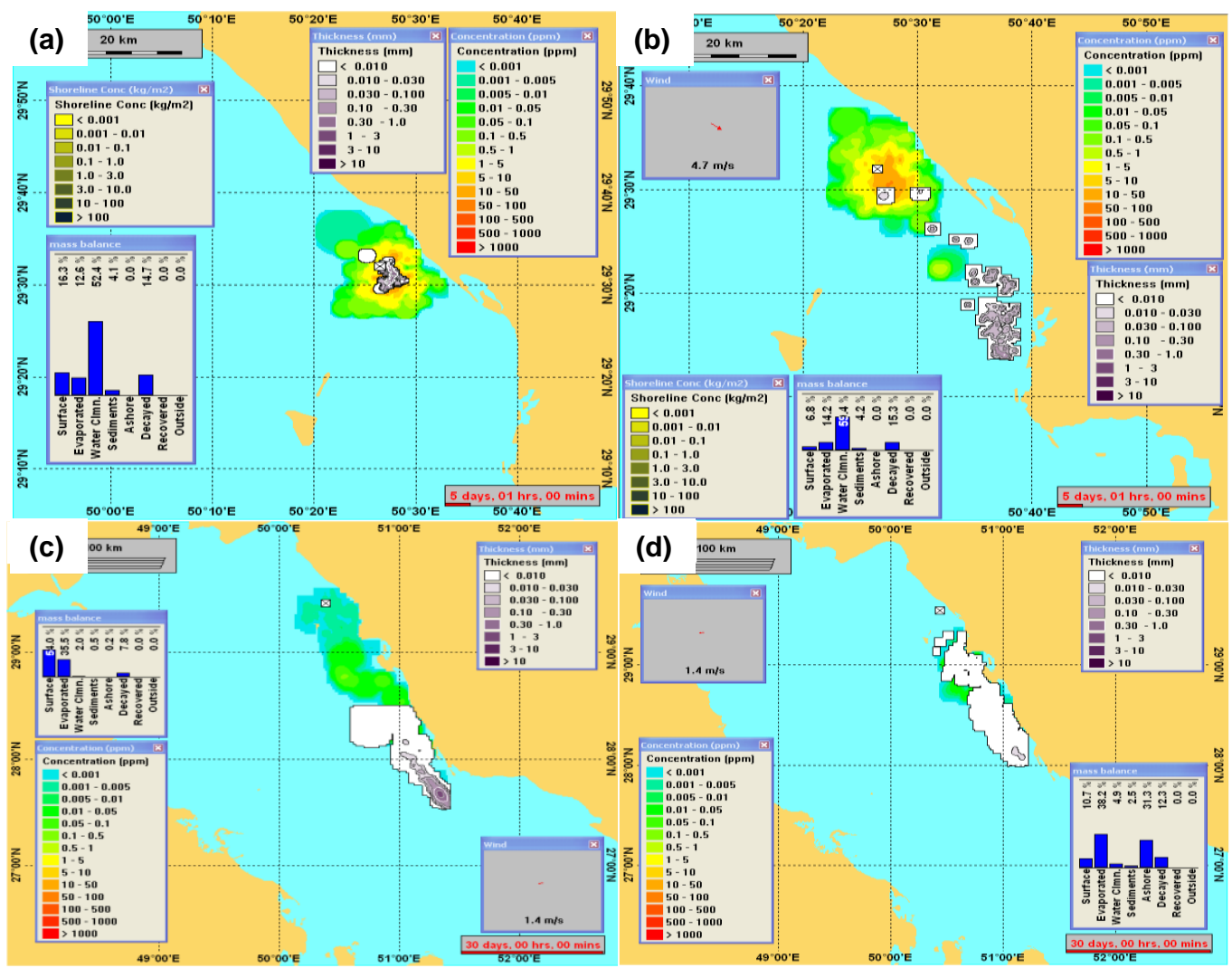

Figure 4. Snapshot of surface and subsurface distribution of the total hydrocarbon concentrations (THC) and surface oil: (a) 5 days after the hypothetical blowout in scenario No. 2 without considering the effects of wind; (b) 5 days after the hypothetical blowout in scenario No. 2 with considering the effects of wind; (c) 30 days after the hypothetical blowout in scenario No. 8; (d) 30 days after the hypothetical blowout in scenario No. 9

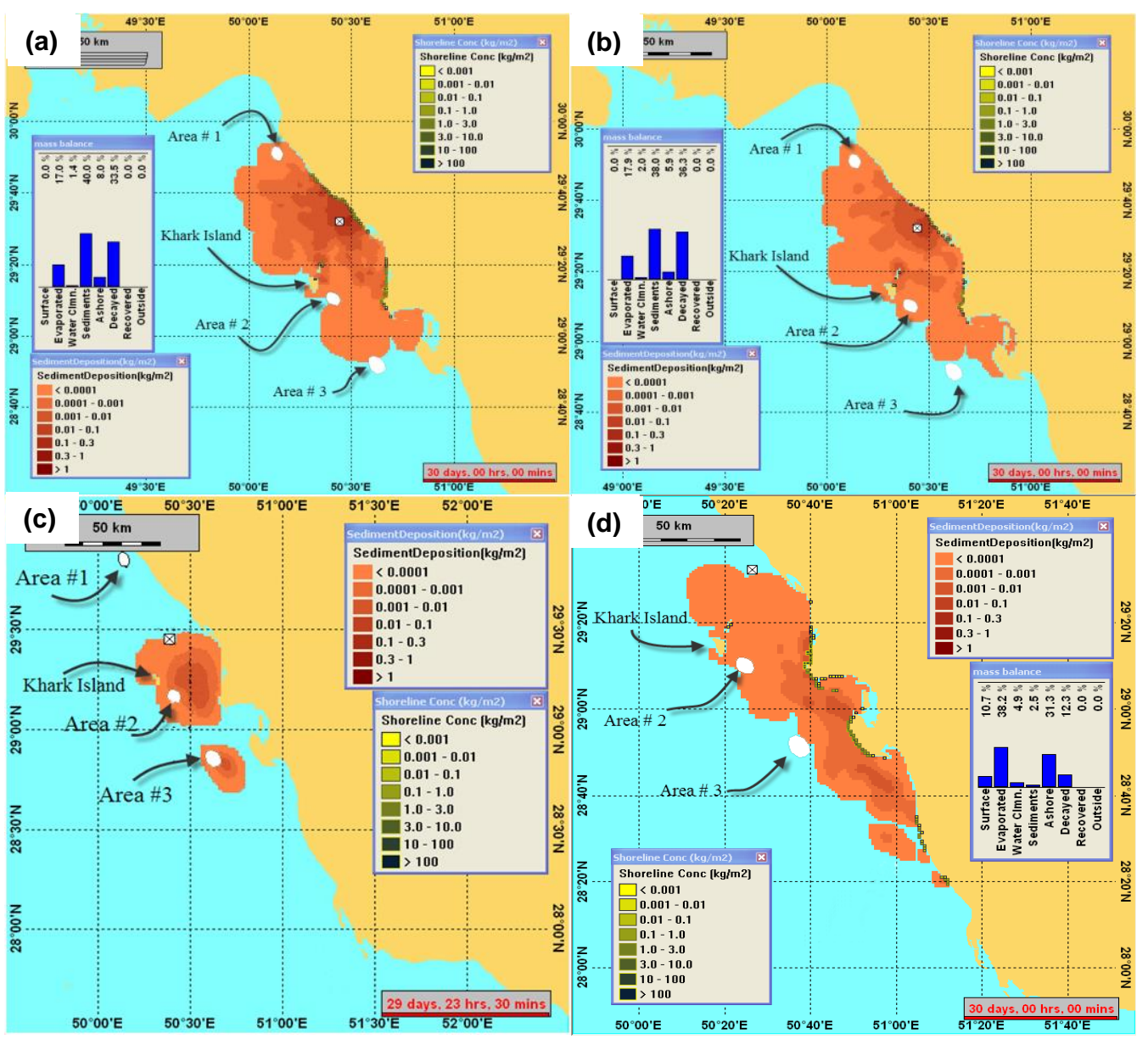

Figure 5. Distribution of ashore and deposited oil 30 days after the beginning of the hypothetical blowout: (a) scenario No. 2; (b) scenario No. 3; (c) scenario No. 8; (d) scenario 

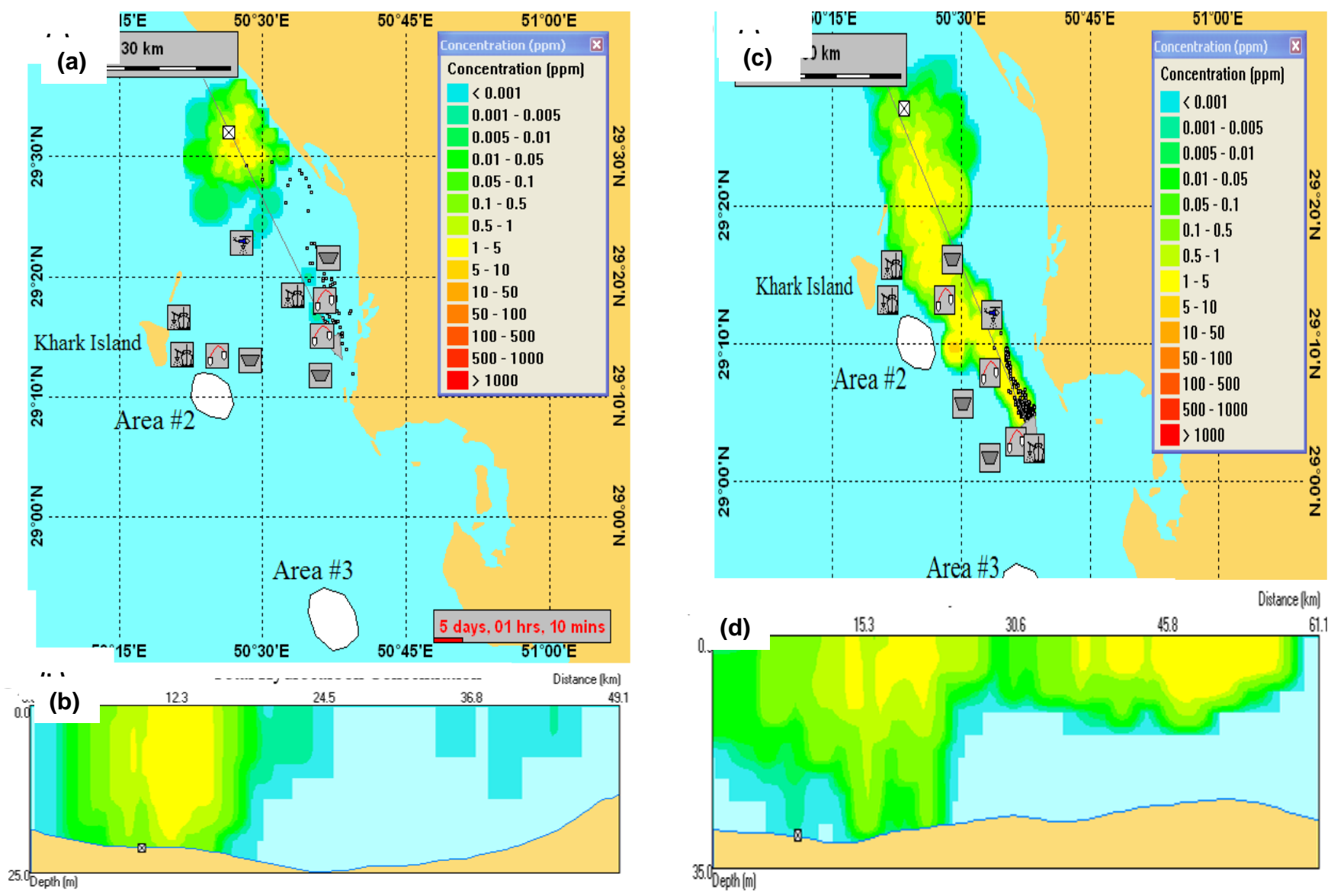

Figure 6. Snapshot of surface (black) and subsurface distribution of the Total Hydrocarbon Concentrations (THC), 5 days after the hypothetical blowout: (a) plan view of the field in scenario No. 2; (b) vertical cross-section of the water column drawn from NorthWest to South-East in scenario No. 5; (c) plan view of the field in scenario No. 9; (d) vertical cross-section of the water column drawn from North-West to South-East in scenario No. 9

Figure 6 presents snapshots of surface and subsurface distribution of the Total Hydrocarbon Concentrations (THC), in scenario No. 5 and 9 just 5 days after the hypothetical blowout. In scenario No. 4 and 5, response action cannot postpone hitting spilled oil to the coast. In scenario No. 4 (with no chemical dispersant), approximately $5.0 \%$ of the spilled oil could be recovered, and there is $4.5 \%$ reduction in the stranded oil. In scenario No. 5 (with chemical dispersant), approximately $5.0 \%$ of the spilled oil could be recovered and there is a $4.8 \%$ reduction in the stranded oil. Dispersion of some part of surfaced oil by chemical dispersant in scenario No. 5 did not affect the amount of recovered oil by boom-skimmer systems. The low amount of surfaced oil is one reason for the low amount of cleaned oil, despite such recovery system. Just during the first 18 days of simulation, less than $10 \%$ of the spilled oil remained at the water surface. The boomskimmer systems can only clean the oil at the surface and the oil in the top part of the water column. Therefore, the low amount of recovered spilled oil is reasonable. In scenario

No. 6 all recovery systems were mobilized with a delay (within 48 hours) after announcing the accident and approximately $2.5 \%$ (it was $4.8 \%$ with no delay) of the spilled oil was recovered, and there was $4.0 \%$ reduction in the stranded oil. Since spilled oil remained at the water surface for a short time, a fast response action is essential.

Reed et al., 1999 defined a Predicted No-Effect Concentration (PNEC) of 2 ppb for fish spawning. Given that the PNEC for Khark prawn spawning is not determined, PNEC of 2 ppb was also considered in this study. The water volume with hydrocarbon concentration greater than $2 \mathrm{ppb}$ in the selected area during simulation of scenarios (No. 2, 5, 7 and 8) are presented as time-series in Figure 7.Only the dissolved hydrocarbon concentration of the area \#2 exceeds $2 \mathrm{ppb}$ in scenario No. 2 (with no response action),. It was occurred 21 days after the start of the blowout. Due to use of chemical dispersant in scenario No. 5, the volume of water with more than $2 \mathrm{ppb}$ PNEC is increased in area \#1 and \#2. In scenario No. 8 (with no response action), dissolved hydrocarbon concentrations exceed $2 \mathrm{ppb}$ in area \#2 and area \#3. Comparing results of scenarios No. 8 and 9, it found that response action in scenario 9 has no significant effect on reduction of hydrocarbon concentrations in the selected areas. As a result, employing chemical dispersant has a reverse effect on the Khark seabed habitats. 


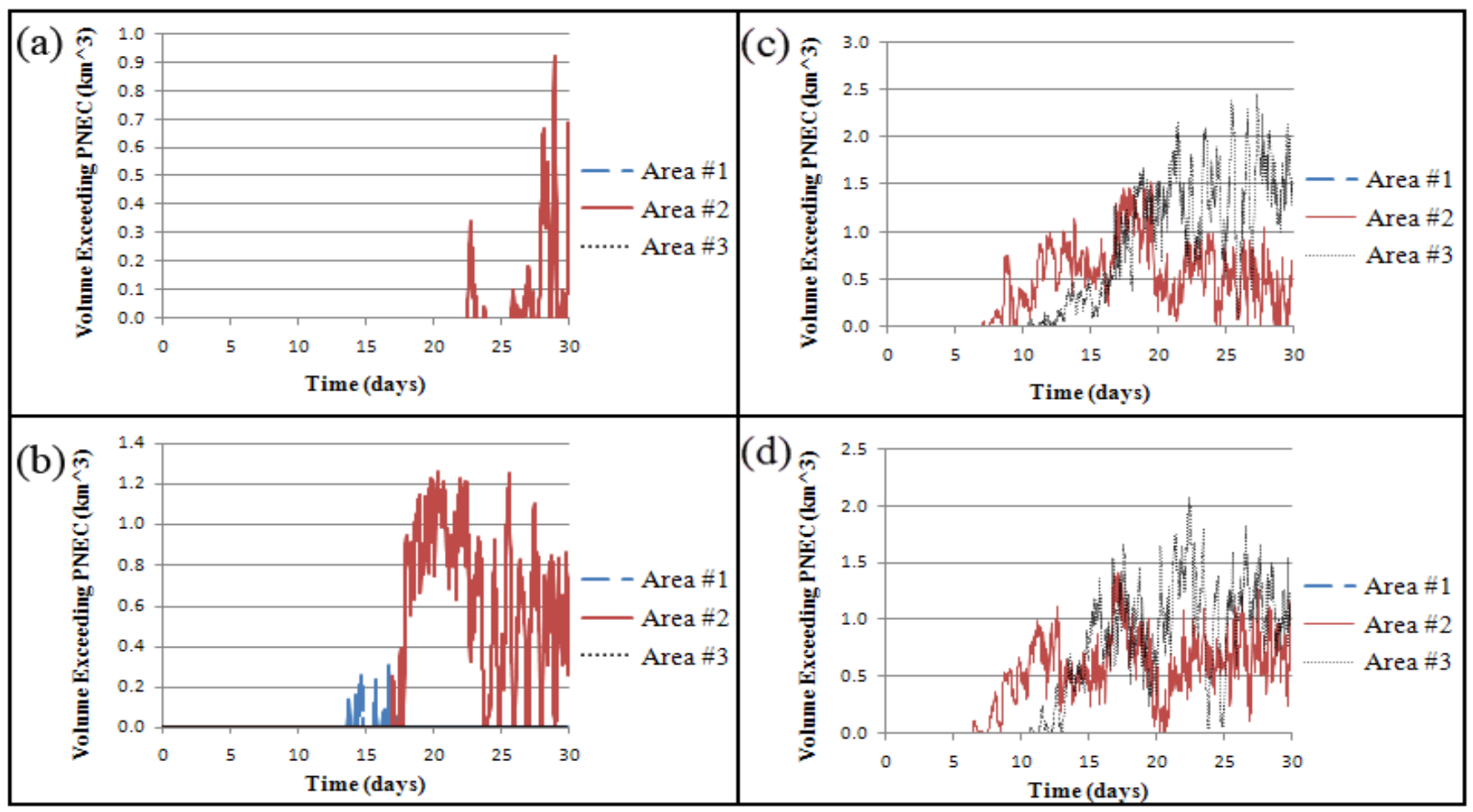

Figure 7. Volume of water exceeding a Predicted No-Effect Concentration (PNEC) of 2 ppb: (a) scenario No. 2; (b) scenario No. 5; (c) scenario No. 8; (d) scenario No. 9

\section{Conclusions}

OSCAR as the oil spill analysis model was successfully verified in the Persian Gulf based on Mina Al-Ahmadi oil spill field observed data. The oil path and predicted time resulted from the OSCAR model were in a very good agreement with the field observed data.

The work reported here includes analyses of the specific potential of oil blowout from subsea pipelines located between Iran mainland and Khark Island. The analyses of spilled oil scenarios in Khark area carried out by combined OSCAR 3-dimensional model. Related results indicate that, the wind is the dominant factor for the fate and trajectory of the spilled oil in Khark area and the role of tidal currents are much less than wind. Due to wind condition in Khark area, the South-East coast of Khark has the maximum oil contamination potential. Also by changing the position of the oil blowout, the effect of oil on the Khark area would extremely change. A significant part of the spilled oil from the pipeline will affect the environment by depositing on the seabed. The reason for high level of entrainment and dispersion of oil in the water column is the high-speed blowout from the pipeline in form of a jet. Oil droplets in the water column have a tendency to deposit on the seabed in shallow water depths like Khark area and are mostly influenced by the current. The hypothetical spilled oil extremely threats the Khark area environment and especially the prawns. Some oil spill scenarios were investigated to evaluate the effects of oil spill response actions in order to reduce potential consequences. Oil blowout in case of overall rupture of the pipeline cross section will be a disaster and the level of defined response action is insufficient. In the case of the blowout from a hole, mechanical recovery equipment systems reduce the potential impact of surface oil on the environment, but it cannot eliminate all the potential consequences. Dispersant aircrafts may reduce the potential of surface pollution effects but they may increase the potential effects of spilled oil on the prawns by increasing the amount of oil in the water column and sedimentation. The reason for the low amount of cleaned oil is the low amount of surface oil. Generally, such level of defined response, not only may have a low efficiency to reduce the potential damages on the environment, but also may increase the potential environmental hazards for the local prawns due to the utilization of chemical dispersants.

\section{Acknowledgment}

The authors would like to thank Professor Mark Reed for his valuable supports. We would also like to acknowledge SINTEF research organization for providing us with MEMW-OSCAR model. This research was supported by the Iranian Oil Terminals Company (IOTC), so special thanks also go to the members of IOTC: Mrs. Aboughadare, Morshed, and Sardar. Their advice is appreciated.

\section{References}

1- Lehr, W., Cekirge, H., (1979), GULFSLICK I, a computer simulation of oil spill trajectories in the Arabian Gulf, Research Institute, KFUPM, 25.

2- Al-Rabeh, A.H., Cekirge, H.M., Gunay, N., (1991), Modeling the fate and transport of A-Ahmadi oil spill, Water, Air and Soil Pollution 65, 257-279. 
3- Proctor, R., Eliott, A., Flather, R.A., (1994), Modeling tides and surface drift in the Persian GulfApplication to the Gulf oil spill, Continental Shelf Research 14, 531-545.

4- Sabbagh Yazdi, S.R., (2006), Coupled solution of oil slick and depth averaged tidal currents on threedimensional geometry of Persian Gulf, International Journal of Environmental Science and Technology 2 (4), 309-317.

5- Elhakeem, A.A., Elshorbagy, W., Chebbi, R., (2007), Oil spill simulation and validation in the Persian Gulf with special reference to the UAE coast, Water Air Soil Pollution 184, 243-254.

6- Howlett, E., Jayko, K., Isaji, T., Anid, P., Gary, M., Francois, S., (2008), Marine forecasting and oil spill modeling in Dubai and the Gulf region, Dubai, COPEDEC 7.

7- Badri, M.A., Azimian, A. R., (2010), Oil spill model based on the Kelvin wave theory and artificial wind field for the Persian Gulf, Indian Journal of Marine Science 39 (2), 165-181.

8- Farzingohar, M., Zelina, Z.I., Yasemi, M., (2011), Oil spill modeling of diesel and gasoline with GNOME around Rajaee Port of Bandar Abbas, Iranian Journal of Fisheries Sciences 10 (1), 35-46.

9- Ranjbar, P., Shafieefar, M., Rezvandoost, J., (2014), Modeling of oil spill and response in support of decreasing environmental oil effects case study: blowout from Khark subsea pipelines (Persian Gulf), International Journal of Environmental Research 8 (2), 289-296.

10- Rezvandoost, J., Shafieefar, M., Ranjbar, P., Arjmand, E., (2013), Simulation of Hypothetical Oil Spill from Platforms of Bahregansar Oilfield in the Persian Gulf, In Proc. of the Regional Organization for the Protection of the Marine Environment (ROPME), Kish, Iran.

11- Ranjbar, P., Shafieefar, M., Rezvandoost, J., (2011), Hydrodynamic study of accidental sub-sea oil blowout: case study of Khark island pipelines blowout, Proceedings of $10^{\text {th }}$ Iranian Hydraulic Conference, University of Gilan, Gilan, Iran.

12- IOTC (Iranian Oil Terminals Company), (2011), Khark island database.

13- Reed, M., Aamo, O.M., Daling, P.S., (1995a), Quantitative analysis of alternate oil spill response strategies using OSCAR, Spill Science and Technology 2 (1), 67-74.

14- Aamo, O.M., Reed, M., Downing, K., (1996), Calibration, verification, and sensitivity analysis of the SINTEF oil spill contingency and response (OSCAR) model system, SINTEF, Report 42.4048.00/01/96.

15- Aamo, O.M., Reed, M., Daling, P.S., Johansen, O., (1993), A laboratory-based weathering model: PC version for coupling to transport models, Proceedings of the 1993 Arctic and Marine Oil Spill Program (AMOP) Technical Seminar, 617-626.
16- Daling, P.S., Brandvik, P.J., Mackay, D., Johansen, O., (1990), Characterization of crude oils for environmental purposes, Oil \& Chemical Pollution 7, 199-224.

17- Reed, M., French, D., Rines, H., Rye, H., (1995b), A three dimensional oil and chemical spill model for environmental impact assessment, Proceedings of the International Oil Spill Conference 61-66.

18- Johansen, Ø., (2000), DeepBlow - A Lagrangian plume model for deep water blowouts, Spill Science \& Technology Bulletin, Vol. 6, No. 2: 103-111.

19- Aamo, O.M., Reed, M, Daling, P.S., (1995), Evaluation of environmental consequences and effectiveness of oil spill response operations with a possible change in first line response at the Veslefrikk field, SINTEF, Report 95.006.

20- DHI, (2007), MIKE 21 flow model FMhydrodynamic module user guide.

21- IPMO (Iranian Port and Maritime Organization), (2011), Water level measurement data base.

22- ECMWF (European Centre for Medium-Range Weather Forecasts), (2011), [http://data.ecmwf.int/].

23- Smith, Sandwell, (1994, 1997), [http://topex.ucsd.edu/marine_topo/mar_topo.html]. 24- Reed, M., Ekrol, N., Rye, H., Turner, L., (1999), Oil spill contingency and response (OSCAR) analysis in support of environmental impact assessment offshore Namibia, Spill Science and Technology Bulletin 5 (1), 29-38.

25- Reed, M., Rye, H., Johansen, Ø., Durgut, I., Hetland, B., Høverstad, B., Ditlevsen, M., Brönner, U., Arslanoglu, Y., Ekrol, N., Aamo, O.M., Downing, K., (2011), Technical description and verification tests of the SINTEF marine environmental modeling workbench (MEMW), SINTEF, Report STF66 F01044. 26- Niamaimandi, N., (2011), The life cycle of green tiger prawn (Penaeus Semisulcatus, De Haan, 1844) in the Iranian territorial waters of Persian Gulf, Iranian Fisheries Research Organization (IFRO) - Shrimp Research Center of Iran.

27- Reed, M., Turner, C., Odulo, A., (1994a), The role of wind and emulsification in modeling oil spill and surface drifter trajectories, Spill Science and Technology 2, 143-157.

28- Reed, M., French, D., Rines, H. (1994b), Numerical simulation of biological effects of oil spills, J. Adv. Marine Technol. Conf., 11, 65-90.

29- Al-Rabeh, A. H., Cekirge, H. M., Gunay, N. (1992), Modeling the fate and transport of Al-Ahmadi oil spill, Water and Air Pollution, 65, 257-279.

30- United States Defense Mapping Agency's digital chart of the world database, [http://www.nlh.no/ikf/gis/dcw/]. 